\title{
Characterization of Ultradispersed Aluminum
}

\author{
Randall L. Simpson \\ Jon L. Maienschein \\ Rosalind W. Swansiger \\ Frank Garcia \\ Dale H. Darling
}

December 8, 1994

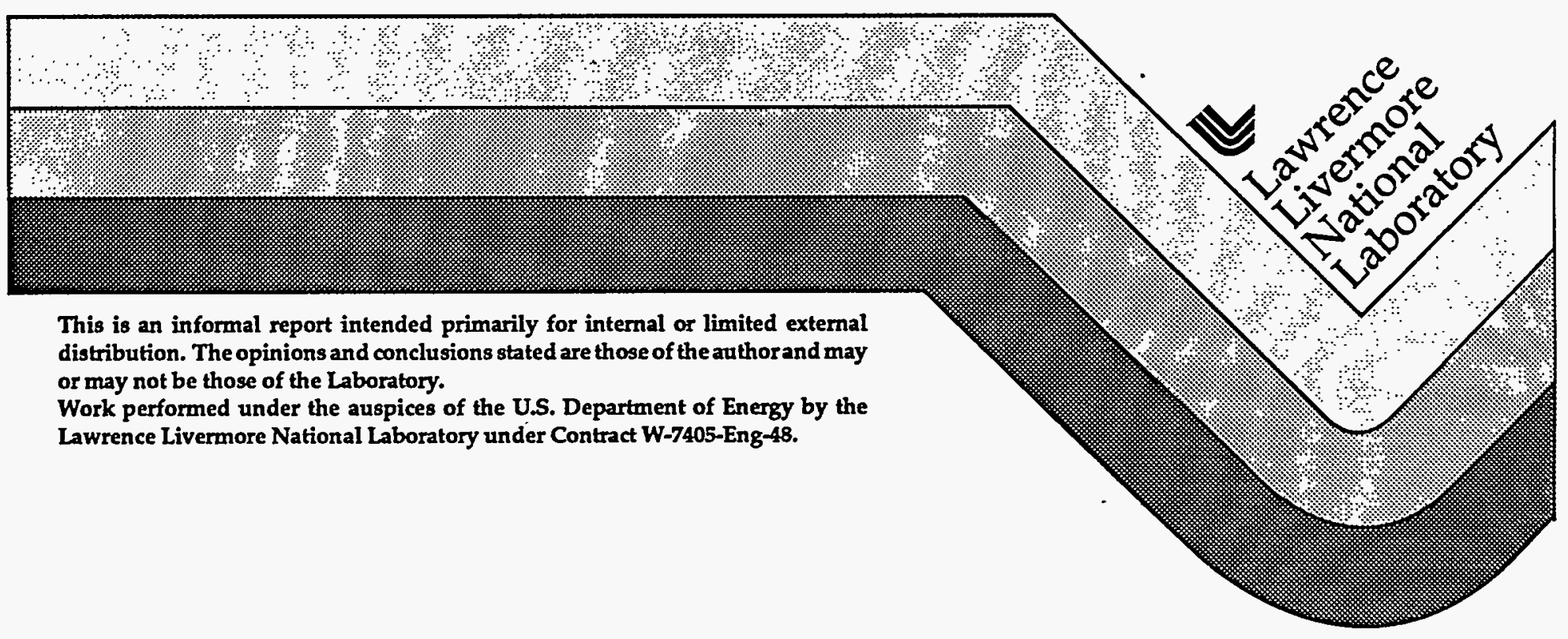

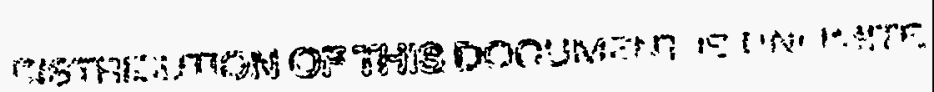




\section{DISCLAIMER}

This document was prepared as an account of work sponsored by an agency of the United States Government. Neither the United States Government nor the University of California nor any of their employees, makes any warranty, express or implied, or assumes any legal liability or responsibility for the accuracy, completeness, or usefulness of any information, apparatus, product, or process disclosed, or represents that its use would not infringe privately owned rights. Reference herein to any specific commercial products, process, or service by trade name, trademark, manufacturer, or otherwise, does not necessarily constitute or imply its endorsement, recommendation, or favoring by the United States Government or the University of Californiz. The viewsand opinions of authors expressed herein do not necessarily state or reflect those of the United States Government or the University of California, and shall not be used for advertising or product endorsement purposes.

This report has been reproduced directly from the best available copy.

Available to DOE and DOE contractors from the Office of Scientific and Technical Information P.O. Box 62, Oak Ridge, TN 37831

Prices available from (615) 576-8401, FTS 626-8401

Available to the public from the National Technical Information Service

U.S. Department of Commerce 5285 Port Royal Rd., Springfield, VA 22161 


\section{DISCLAIMER}

This report was prepared as an account of work sponsored by an agency of the United States Government. Neither the United States Government nor any agency thereof, nor any of their employees, make any warranty, express or implied, or assumes any legal liability or responsibility for the accuracy, completeness, or usefulness of any information, apparatus, product, or process disclosed, or represents that its use would not infringe privately owned rights. Reference herein to any specific commercial product, process, or service by trade name, trademark, manufacturer, or otherwise does not necessarily constitute or imply its endorsement, recommendation, or favoring by the United States Government or any agency thereof. The views and opinions of authors expressed herein do not necessarily state or reflect those of the United States Government or any agency thereof. 


\section{DISCLAIMER}

Portions of this document may be illegible in electronic image products. Images are produced from the best available original document. 


\title{
Characterization of Ultradispersed Aluminum
}

\author{
Randall L. Simpson, Jon L. Maienschein, \\ Rosalind W. Swansiger, Frank Garcia, Dale H. Darling
}

(510) 423-0379

\section{Introduction}

We received samples of ultradispersed aluminum from the U.S. Army at MICOM, which had been produced by electrically exploding aluminum wires in an argon atmosphere. This ultradispersed aluminum reportedly was comprised of very small particles of aluminum that were not significantly oxidized and that were stable in air. These attributes make it attractive as a component in composite explosives or propellants where a rapid aluminum reaction is desired, perhaps for enhanced early time metal acceleration through rapid aluminum reaction and energy release, or for more complete reaction as a result of the small particle size. The small particle size may offer advantages in vulnerability of energetic materials. In addition, MICOM reported unusual burn rate pressure dependence of propellants formulated with the ultradispersed aluminum.

The ultradispersed aluminum reportedly contained significant quantities of argon, perhaps as a previously unknown aluminum/ argon compound.

Furthermore, the material showed a significant exotherm when heated in the DSC, leading to the interpretation by others that it was itself an energetic material through an unknown mechanism of energy release. Because of the curious nature of these indications and the interest in the ultradispersed aluminum in the energetic materials community, we undertook characterization studies to resolve the following questions:

1. Particle size and morphology.

2. Extent of oxidation of aluminum.

3. Stability of material in air at ambient and elevated temperature.

4. Presence of argon in the material (on the surface, occluded in the bulk aluminum, or as a compound with aluminum).

5. Verification of exotherm and identification of its source.

We studied particle morphology with scanning electron microscopy (SEM), micropycnometry, and gas adsorption surface area measurement (BET). We determined the material composition using spark emission spectroscopy, protonand helium- Rutherford backscattering (RBS), particle induced $x$-ray induced emission (RBS/PIXIE), X-ray fluorescence, and scanning Auger spectroscopy. We analyzed the thermal stability and reaction exotherms with differential scanning calorimetry (DSC) and simultaneous differential thermal analysis/ thermogravimetric analysis (DTA/TGA).

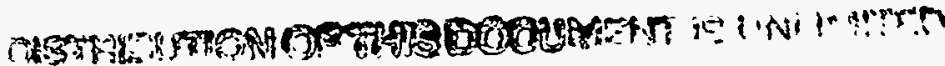

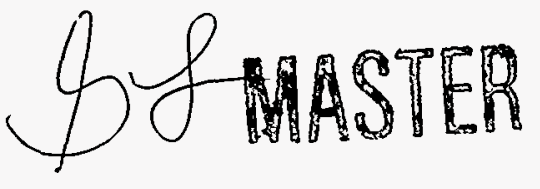


We found that the ultradispersed aluminum is an agglomeration of very small spherical aluminum particles, with a large surface area. There is very little oxidation, and the sample density is that of pure aluminum. There is essentially no argon present on the surface or in the bulk material, and other impurities are present in very small amounts. The aluminum is stable in air at $20^{\circ} \mathrm{C}$, and is only slightly degraded at $700^{\circ} \mathrm{C}$. The exotherm reported by others at elevated temperature is caused by reaction of the very-reactive aluminum with residual moisture in the DSC or DTA/TGA apparatus; when the moisture is removed by flushing, the exotherm disappears and the ultradispersed aluminum thermal response is identical to that of standard aluminum. In short, the inexplicable reports of an aluminum-argon compound and of an exothermic reaction from the ultradispersed aluminum are in fact not borne out by our studies, but the ultradispersed aluminum is a stable, non-oxidized, small particle, highly-reactive form of aluminum that remains of interest in energetic materials formulations.

\section{Morphology studies}

\section{Scanning Electron Microscopy}

Scanning electron micrographs of ultradispersed aluminum and of standard aluminum particles (Alcoa 8122 spherical aluminum, $\approx 20 \mu \mathrm{m}$ particle diameter) are shown in Figures 1-4. Figure 1 shows both materials at 1000x magnification. The ultradispersed aluminum particle is about $40 \mu \mathrm{m}$ in diameter, but is clearly not a solid particle; the standard aluminum particles are $5-40 \mu \mathrm{m}$ in diameter and look like solid misshapen spheres. At magnification of 3000x, in Figure 2, the ultradispersed aluminum appears sponge-like in nature, while the standard aluminum retains its solid appearance. Figure 3 shows the samples at 10,000x. The ultradispersed aluminum appears to be an agglomeration of very small spherical particles with a very porous structure, while the standard aluminum particle is one solid sphere. Figure 4 shows the ultradispersed aluminum at 30,000x magnification, where we clearly see the spherical nature of the submicron particles $(0.1-0.3 \mu \mathrm{m}$ diameter) that agglomerate to form the larger porous structure.

When ultradispersed aluminum is ramped to $700^{\circ} \mathrm{C}$ in the SEM under high vacuum, there is some consolidation of the submicron particles, as shown in Figure 5. We can see some sheetlike structure in the micrographs at 1000x and $30000 x$, indicative of partial melting and coalescence of the fine particles. This will lead to a reduction in surface area of the samples. Despite this, the structure is mostly unchanged from that of the unheated samples, indicative of the thermal stability of this material.

\section{Micropycnometry}

We measured the density of the ultradispersed aluminum powder with a Quantachrome Micropycnometer and helium gas; the density was $2.695 \pm$ $0.059 \mathrm{~g} / \mathrm{cm}^{3}$. This is identical with the density of aluminum (2.70), and significantly different from other possible aluminum compounds: $\mathrm{Al}_{2} \mathrm{O}_{3}$ (3.5-3.9), $\mathrm{Al}_{4} \mathrm{C}_{3}$ (2.36), 
Figure 1. Scanning electron micrographs of ultradispersed aluminum (on left) and standard aluminum particles (on right) at $1000 \times$ magnification. The ultradispersed aluminum $(\approx 40 \mathrm{um}$ diameter) is porous, while the standard aluminum particles $(5-40 \mu \mathrm{m}$ diameter) appear to be solid.
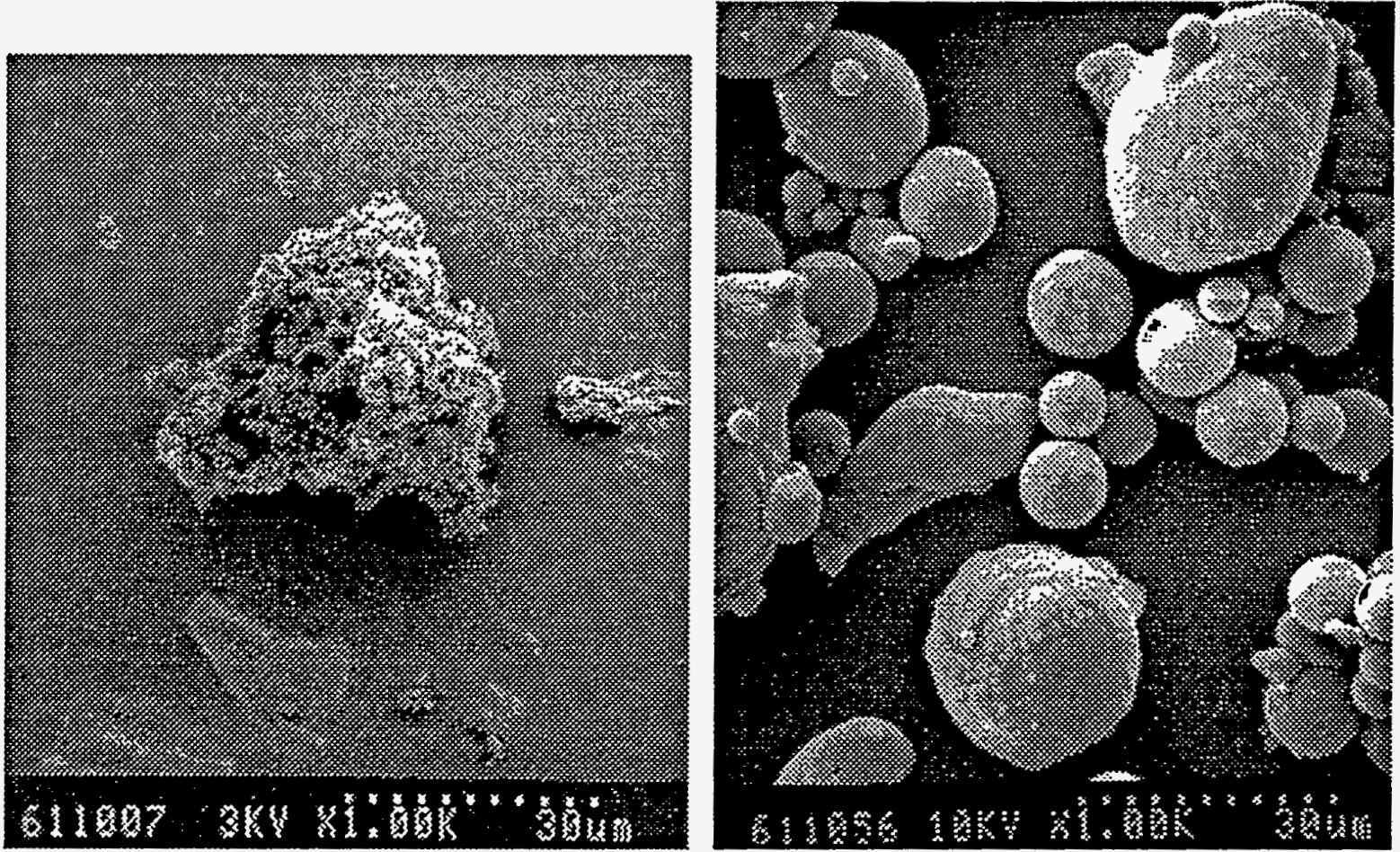

Figure 2. Scanning electron micrographs of ultradispersed aluminum (on left) and standard aluminum particles (on right) at 3000x magnification. The spongelike nature of the ultradispersed aluminum is clearly visible, while the standard aluminum particles are not porous.
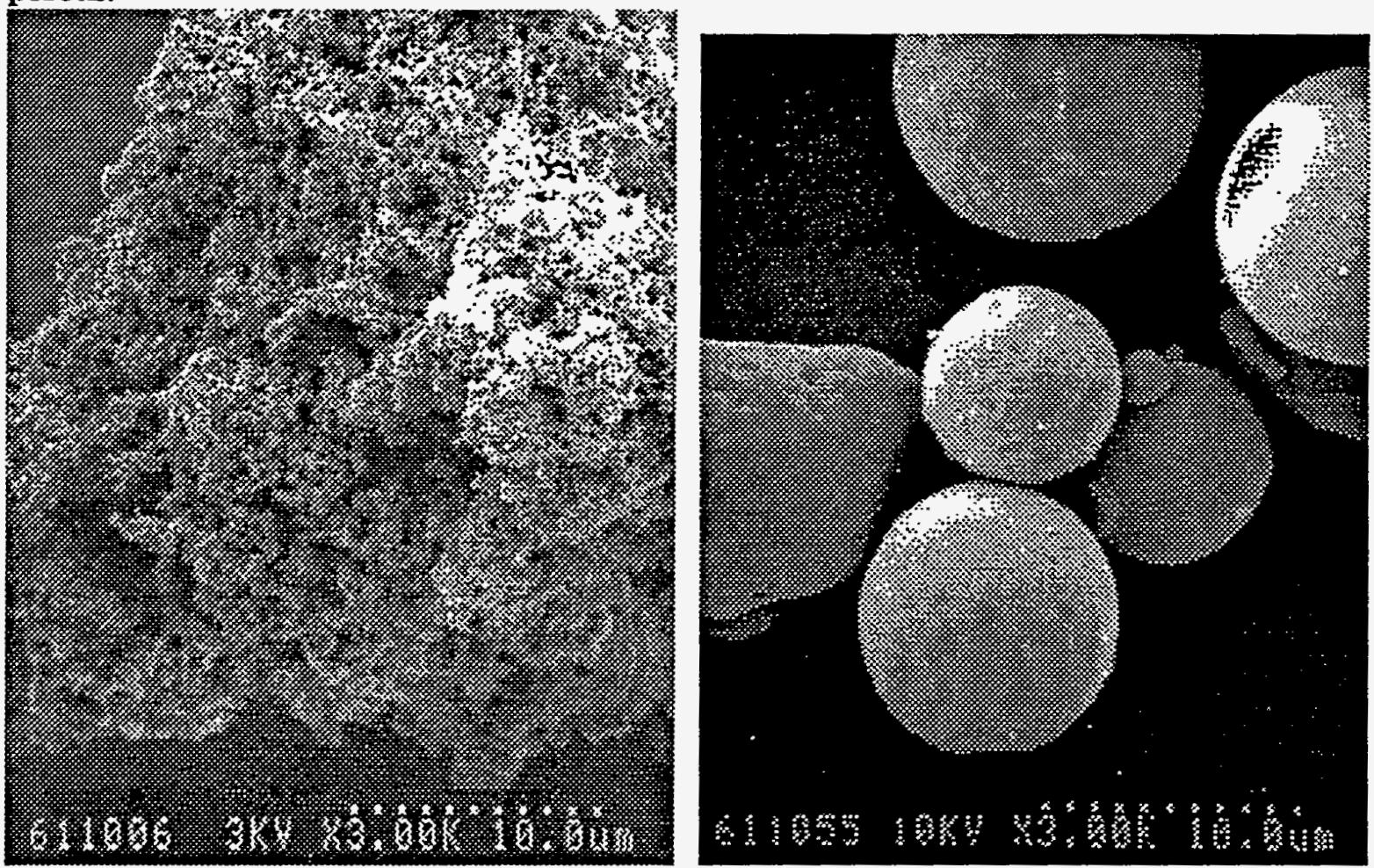
Figure 3. Scanning electron micrographs of ultradispersed aluminum (on left) and standard aluminum (on right) at 10,000x magnification. The ultradispersed aluminum appears to be an agglomeration of very small spherical particles, while the standard aluminum is one large sphere.
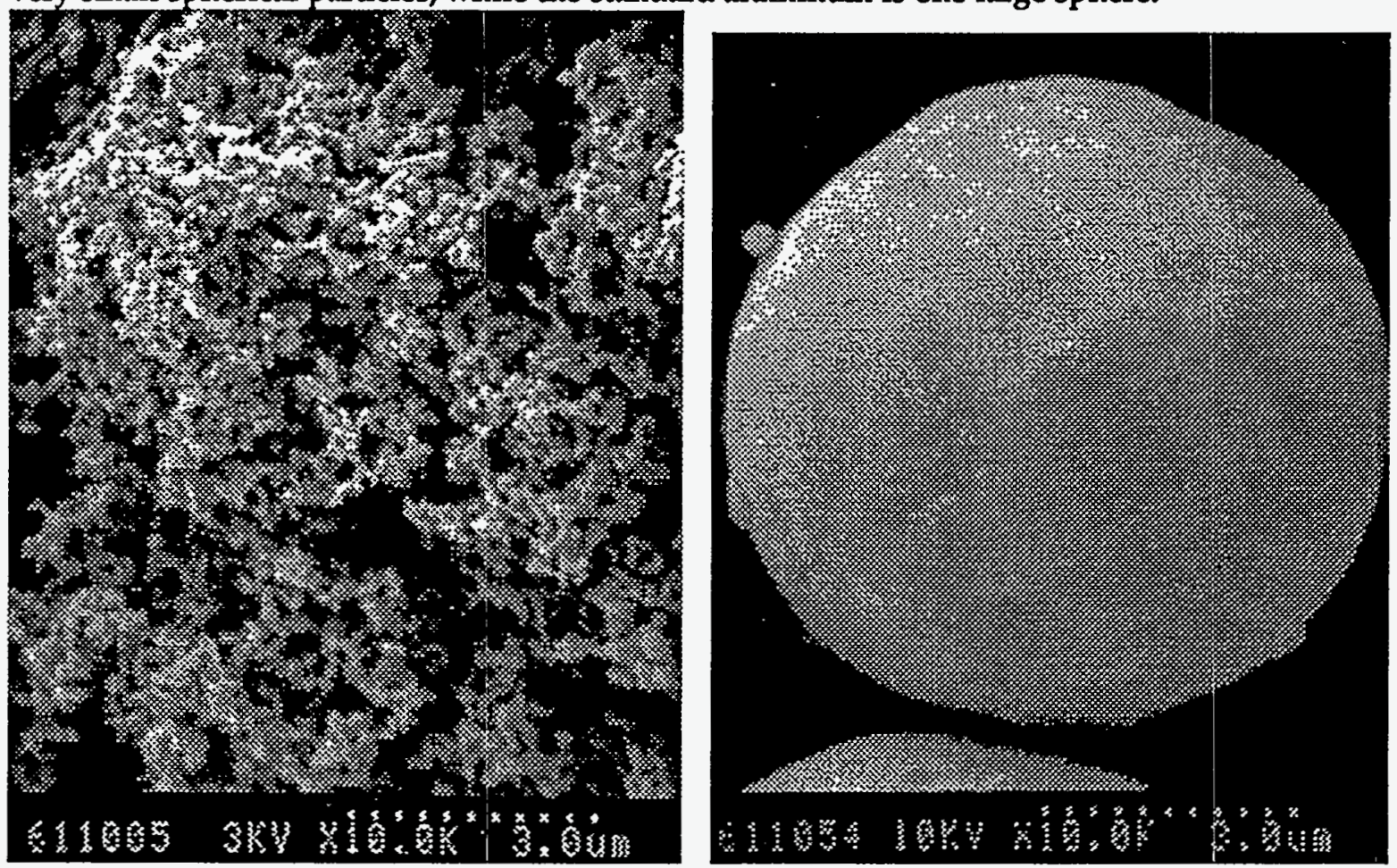

Figure 4. Scanning electron micrograph of ultradispersed aluminum at $30,000 \times$ magnification. The spherical submicron particles that agglomerate to form the spongy structure are clearly visible.

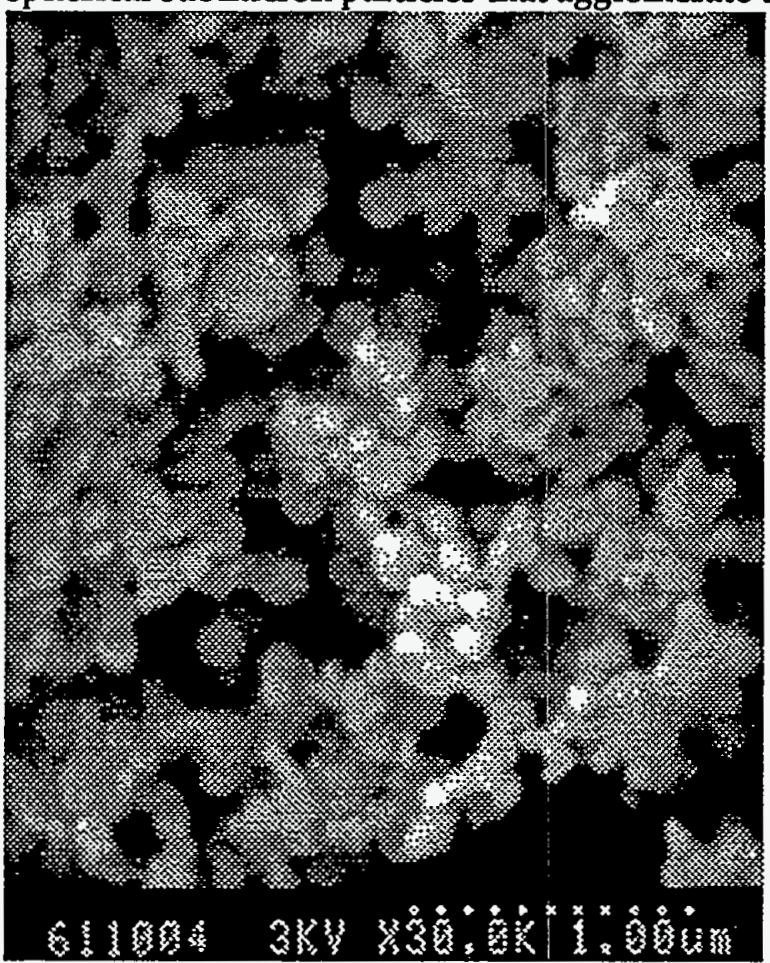


Figure 5. Scanning electron micrographs at 3,000 $x$ and 10,000 $x$ magnification of ultradispersed aluminum that has been heated to $700^{\circ} \mathrm{C}$. Formation of sheetlike structures indicative of partial melting and consolidation of the submicron particles is visible, but the overall porous structure is retained.
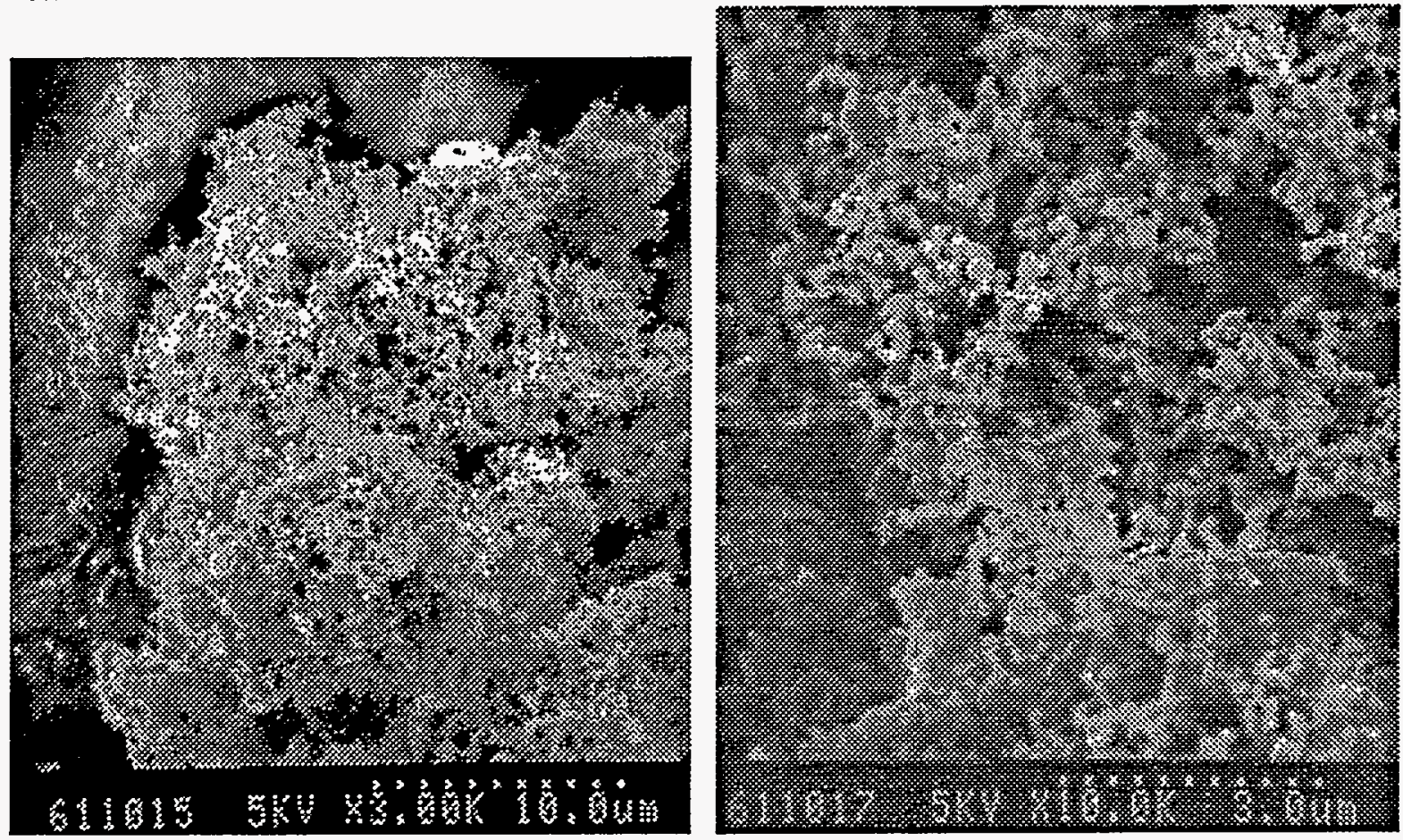

AlN (3.26). This is strong indication that the ultradispersed aluminum is essentially pure aluminum with very little oxidation.

\section{Nitrogen-adsorption Surface Area Measurement}

The BET surface area of the ultradispersed aluminum was measured by nitrogen adsorption after an overnight bakeout at $200^{\circ} \mathrm{C}$ and $10^{-5}$ torr; the surface area was $2.47 \mathrm{~m}^{2} /$ gram.

From the density and surface area data, we can calculate an average particle diameter assuming spherical particles; this is a good assumption based on the SEM photographs. If we neglect inter-particle contact area, we calculate an average particle diameter of $0.9 \mu \mathrm{m}$. However, from the SEM images there clearly is a significant portion of the spherical particle surface area that is in contact with other particles and hence not available for gas adsorption. For fraction $f$ of spherical particle surface that is not available to gas adsorption, the calculated average particle diameter is 0.9 $x(1-f) \mu \mathrm{m}$. Therefore, if we assume that $f=0.4$, the calculated average particle diameter is $0.5 \mu \mathrm{m}$. This is reasonably consistent with the particle sizes seen in Figure 4 , where the submicron particles appear to be $0.1-0.3 \mu \mathrm{m}$ in diameter. 


\section{Compositional analysis}

\section{Spark Emission Spectroscopy}

We analyzed for elemental impurities with spark emission spectroscopy; this technique is not sensitive to noble gases, but does give a semiquantitative analysis of many trace elements. The results are shown in Table 1. The major impurities are iron and silicon. None of the impurities are present at very high levels.

Table 1. Spark emission analysis of impurities in ultradispersed aluminum. Elements with an upper bound on the content were not seen in the analysis, and the values represent the concentration required for positive identification.

\begin{tabular}{cccccccc} 
Element & ppm $_{\mathbf{w}}$ & & Element & ppm $_{\mathbf{w}}$ & & Element & ppm $_{\mathbf{w}}$ \\
\cline { 1 - 4 } \cline { 6 - 7 } $\mathrm{Fe}$ & 1000 & & $\mathrm{Ag}$ & 10 & & $\mathrm{Sn}$ & $<10$ \\
$\mathrm{Si}$ & 500 & & $\mathrm{Mn}$ & 10 & & $\mathrm{Bi}$ & $<10$ \\
$\mathrm{Ti}$ & 300 & & $\mathrm{As}$ & $<100$ & & $\mathrm{Cr}$ & $<10$ \\
$\mathrm{P}$ & 200 & & $\mathrm{Hg}$ & $<100$ & & $\mathrm{Ni}$ & $<10$ \\
$\mathrm{Cu}$ & 80 & & $\mathrm{Ba}$ & $<30$ & & $\mathrm{Ge}$ & $<3$ \\
$\mathrm{Mg}$ & 50 & & $\mathrm{Zr}$ & $<30$ & & $\mathrm{Y}$ & $<3$ \\
$\mathrm{Zn}$ & 30 & & $\mathrm{~Pb}$ & $<30$ & & $\mathrm{~B}$ & $<3$ \\
$\mathrm{Ga}$ & 30 & & $\mathrm{Cd}$ & $<10$ & & $\mathrm{Co}$ & $<1$ \\
$\mathrm{Na}$ & 30 & & $\mathrm{~V}$ & $<10$ & & $\mathrm{Be}$ & $<1$ \\
$\mathrm{Mo}$ & 20 & $\mathrm{In}$ & $<10$ & & $\mathrm{Sr}$ & $<1$ \\
$\mathrm{Ca}$ & 10 & $\mathrm{Nb}$ & $<10$ & & &
\end{tabular}

\section{PIXIE and RBS}

We analyzed ultradispersed aluminum by particle induced $X$-ray emission (PIXIE) and by Rutherford backscattering (RBS), using $2.2 \mathrm{MeV} \mathrm{H}^{+}$and $2.3 \mathrm{MeV} \mathrm{He}^{+}$ ions as the probe ions. The powder sample was mounted on tape and inserted into the accelerator sample chamber for analysis under vacuum. The normal to the sample surface was tilted $15^{\circ}$ toward the X-ray detector, which was oriented $90^{\circ}$ to the incident beam axis. The backscattered ions were measured at $168^{\circ}$ from the sample surface. The beam spot on the specimen was about $1.5 \mathrm{~mm}$ high $\times 1 \mathrm{~mm}$ wide.

PIXIE with protons gave the highest-resolution qualitative elemental composition of the sample. As shown in Figure 6, oxygen, calcium, titanium, and iron are present in addition to aluminum. The $\mathrm{Al}(\mathrm{K})$ pileup signal at $2.97 \mathrm{keV}$ (twice the $\mathrm{Al}(\mathrm{K})$ energy) overlaps any potential $\mathrm{Ar}(\mathrm{K})$ peak at $2.96 \mathrm{keV}$, so we cannot determine the presence of argon by PIXIE. The $\mathrm{Al}(\mathrm{K})$ pileup signal at $4.46 \mathrm{keV}$ (three times the $\mathrm{Al}(\mathrm{K})$ energy) overlaps the $\mathrm{Ti}\left(\mathrm{K}_{\alpha}\right)$ peak at $4.51 \mathrm{keV}$, but the $\mathrm{Ti}\left(\mathrm{K}_{\beta}\right)$ peak at $4.93 \mathrm{keV}$ gives unambiguous evidence for the presence of titanium. 
Figure 6. $X$-ray signal from particle induced $X$-ray emission (PIXIE) analysis of ultradispersed aluminum, using $2.2 \mathrm{MeV} \mathrm{H}^{+}$probe ions.

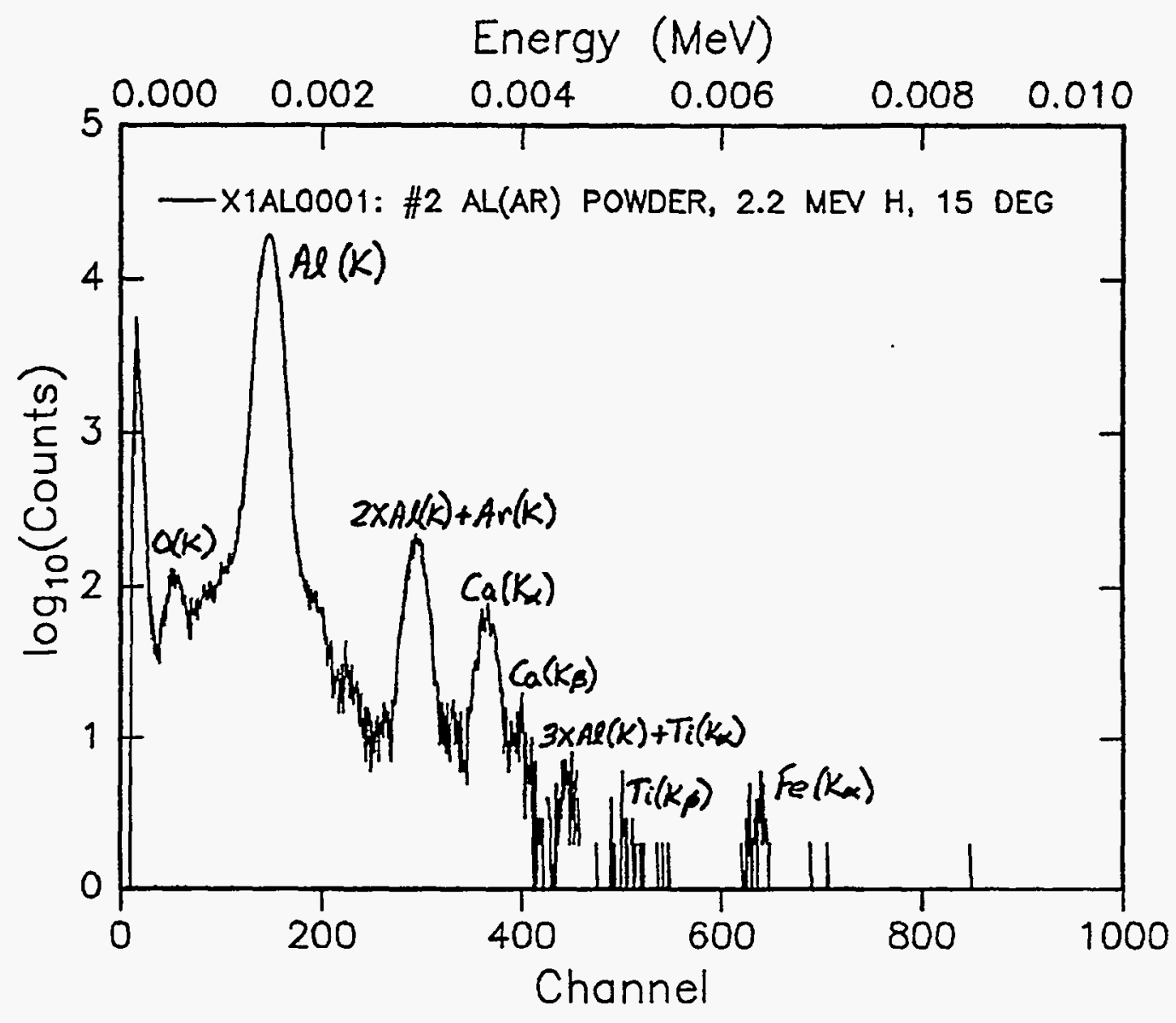

Rutherford backscattering (RBS) provides a spectrum of backscattered ion fluence as a function of energy. Specific elements show up at certain energies, and the width of the spectral features indicate the thickness of the relevant element. Furthermore, by matching the measured spectrum with calculated spectrums (using the program RUMP) based on assumed compositions, we can determine the approximate composition of the sample. RBS data from ultradispersed aluminum are shown in Figures 7 and 8. The entire spectrum, shown in Figure 7, shows a signal shift corresponding to the presence of oxygen as well as the signal due to aluminum. The end of the signal near baseline is magnified in Figure 8. Also shown in Figures 7 and 8 is the calculated spectrum for the best match to the data, with the composition $\mathrm{Al}_{0.927}, \mathrm{O}_{0.07}, \mathrm{Ar} 0.0005, \mathrm{Ca}_{0.001}, \mathrm{Fe}_{0.0015}$; the presence of calcium 
Figure 7. Rutherford backscattering spectrum of ultradispersed aluminum using $2.3 \mathrm{MeV} \mathrm{He}^{+}$ions. Data are shown as dots, and the calculated spectrum is shown as a line. The step due to oxygen is visible. The subscript " $\mathrm{S}$ " corresponds to the energy of the helium backscattered from the indicated element located at the surface of the sample.

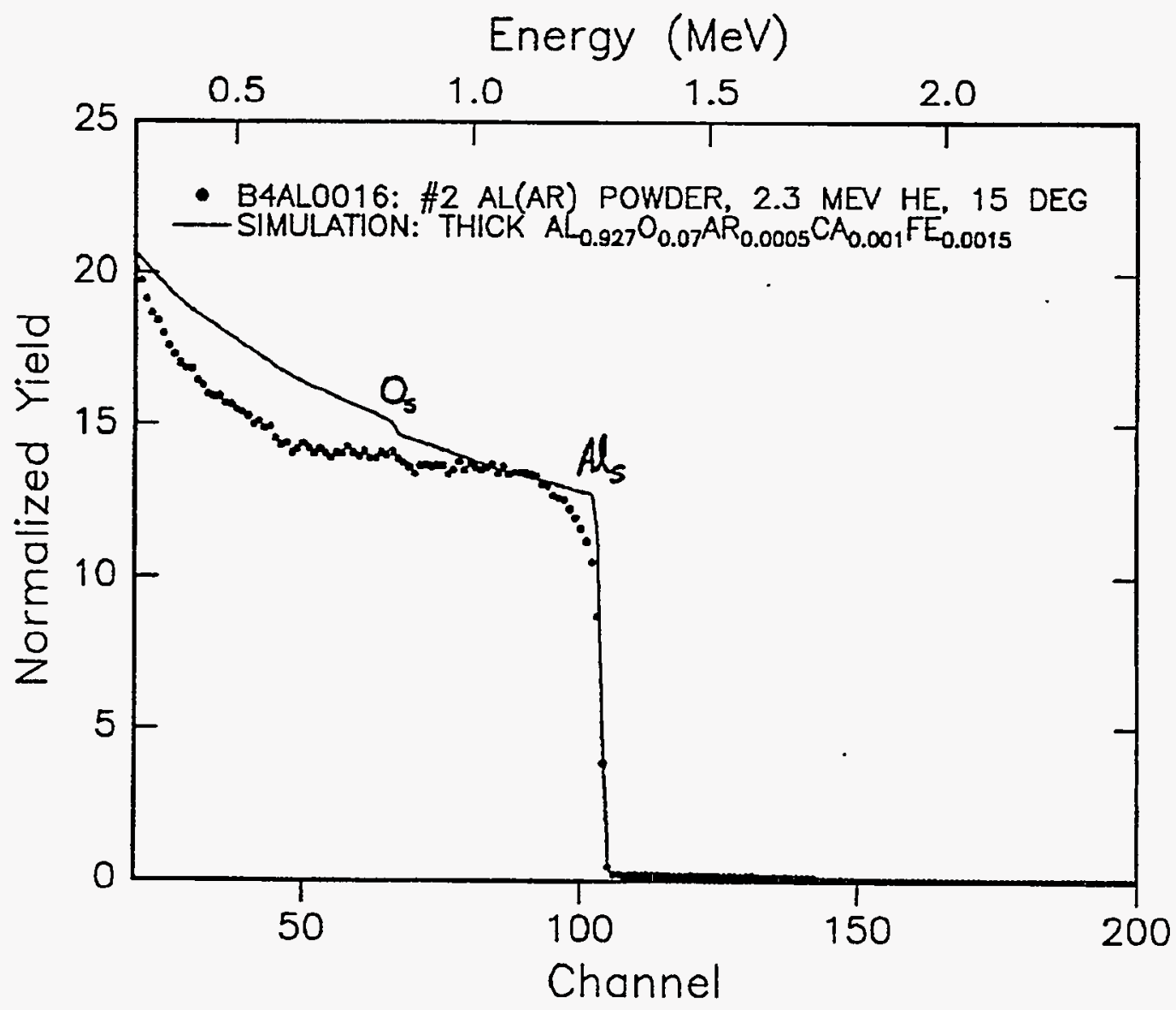

and iron is consistent with their observation with PIXIE. There is no titanium visible in the RBS spectrum despite its occurrence in the PIXIE results, so it is not included in the calculated spectrum. There is evidence of a small amount of an element slightly heavier than iron in the RBS spectrum; however, because there was no associated PIXIE peak, this unidentified element was not included in the calculated RBS spectrum.

The calculated spectrum is based on the assumption of a planar surface of uniform lateral composition; since the ultradispersed aluminum powder mounted on tape does not have this configuration, the data do not exactly match the calculated spectrum. Nonetheless, the net amplitude of the step for oxygen at the surface is matched for an average composition of $7 \pm 2.8 \mathrm{a} \%$. The analysis clearly shows that the argon concentration is less than $0.2 \mathrm{a} \%$, with a value of $0.05 \mathrm{a} \%$ used in the calculated spectrum. Therefore argon is not present in significant quantities in the ultradispersed aluminum. (Note that the width of the (Ar, Ca) step in Figure 8 corresponds to a depth of $0.5 \mu \mathrm{m}$, which is greater than the diameter of the 
Figure 8. Expansion of RBS spectrum in Figure 7 to magnify the heaviest element peaks. A step due to $\mathrm{Ca}$ or Ar, and a step due to iron, are seen. An additional slight step is seen just above the baseline, which may represent another element that was not identified by PLIE analysis. The subscript " $S$ " corresponds to the energy of the helium backscattered from the indicated element located at the surface of the sample.

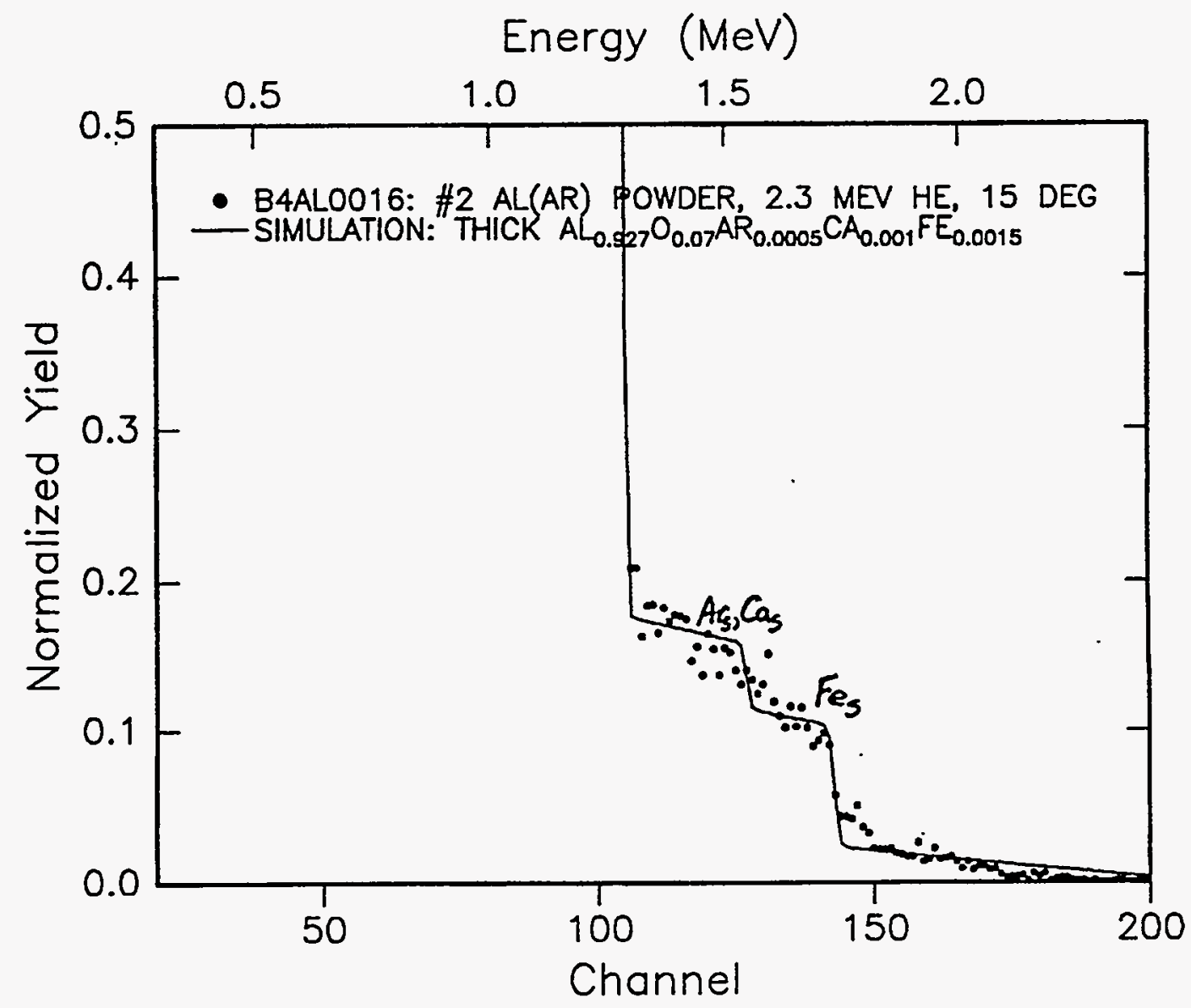

spherical particles; therefore, the RBS analysis includes several layers of particles, insuring measurement of bulk properties of the sample.

If we assume that all of the oxygen is present as an oxide on the particle surface, we can estimate the thickness of the oxide coating on the particles. Using an $\mathrm{Al}_{2} \mathrm{O}_{3}$ density of $3.9 \mathrm{~g} / \mathrm{cm}^{3}$, an average particle size of $0.1 \mu \mathrm{m}$, and an $\mathrm{O} / \mathrm{Al}$ ratio from RBS of 0.076 , we calculate an average oxide thickness of $2 \mathrm{~nm}$. This is somewhat thinner than the typical thickness of native oxide on aluminum. The oxide layer on ultradispersed aluminum was perhaps formed at high temperature during the dispersion process; as a result it may be a more stable oxide with fewer defects than an oxide formed at room temperature. This would explain the thinner nature of the oxide on ultradispersed aluminum, and the unusual stability of the ultradispersed aluminum in air at ambient conditions. 


\section{X-fluorescence spectroscopy}

We used X-ray fluorescence spectroscopy to attempt to detect argon in the ultradispersed aluminum. The region of the spectrum where argon would be present is shown in Figure 9. We saw only the rhodium signal from the X-ray tube, with no signal where the argon is expected. On the basis of this spectrum, the argon concentration is estimated to be $<0.01 \mathrm{a} \%$.

Figure 9. Region of $X$-ray fluorescence spectrum where argon would appear if it were present. The only signals are from rhodium in the $X$-ray tube.

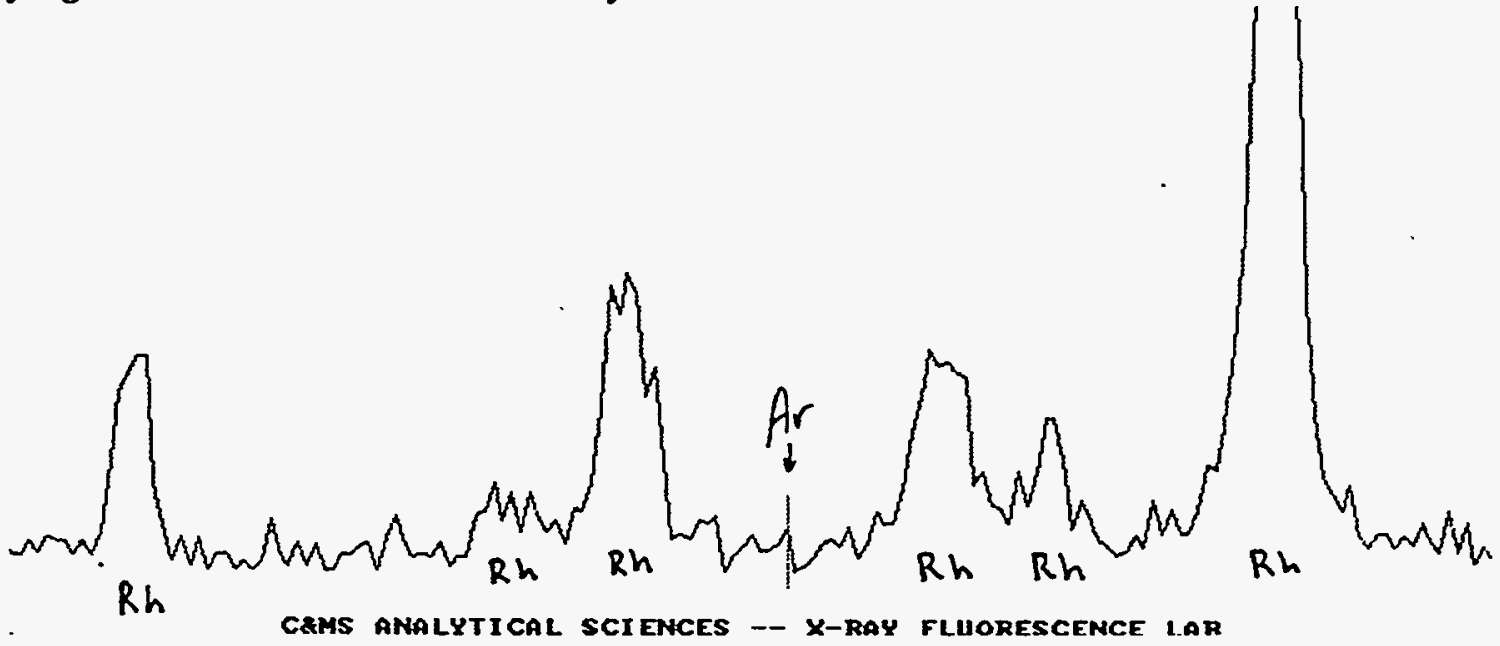

\section{Scanning Auger spectroscopy}

A scanning Auger microprobe (SAM) was used to characterize the ultradispersed aluminum. This technique provides an image of the sample, and also gives elemental composition of specific areas on the sample. Two samples were analyzed. One was obtained by wiping an indium foil across a small amount of powder, causing small particles to be lodged in the soft foil. The second sample was powder that was dropped into a small indentation in indium foil. Both were examined using either 10 or $20 \mathrm{keV}$ incident electron beams with currents of about 30 nanoamps.

In the SAM, the powder appeared clumped together in pieces of $\approx 100 \mu \mathrm{m}$ diameter; the pieces were made up primarily of very fine $(\leq 100 \mathrm{~nm})$ particles. This is consistent with the SEM images shown above. The surfaces of the fine particles were primarily composed of an oxide of aluminum. We also found significant numbers of large aluminum oxide spheres with a diameter of $\approx 2 \mu \mathrm{m}$, and larger (10-30 $\mu \mathrm{m})$ metallic aluminum spheres. These are visible in the SAM image in Figure 10. Carbon, presumably from contamination, was sometimes seen, but no argon was detected. The thickness of the oxides could not be determined since the small particle size precluded useful ion etching; however, from the mean free path of the Auger electrons, we can infer that the oxide layer is on the order of $10 \mathrm{~nm}$ 
thick. This is reasonably consistent with, although somewhat greater than, the $2 \mathrm{~nm}$ thickness calculated above from RBS data; we expect the RBS value to be more accurate since it is based on actual compositional measurements.

Figure 10. Scanning Auger Microprobe (SAM) image of ultradispersed aluminum. Spherical regions identified by Auger spectroscopy as pure aluminum or aluminum oxide are illustrated.

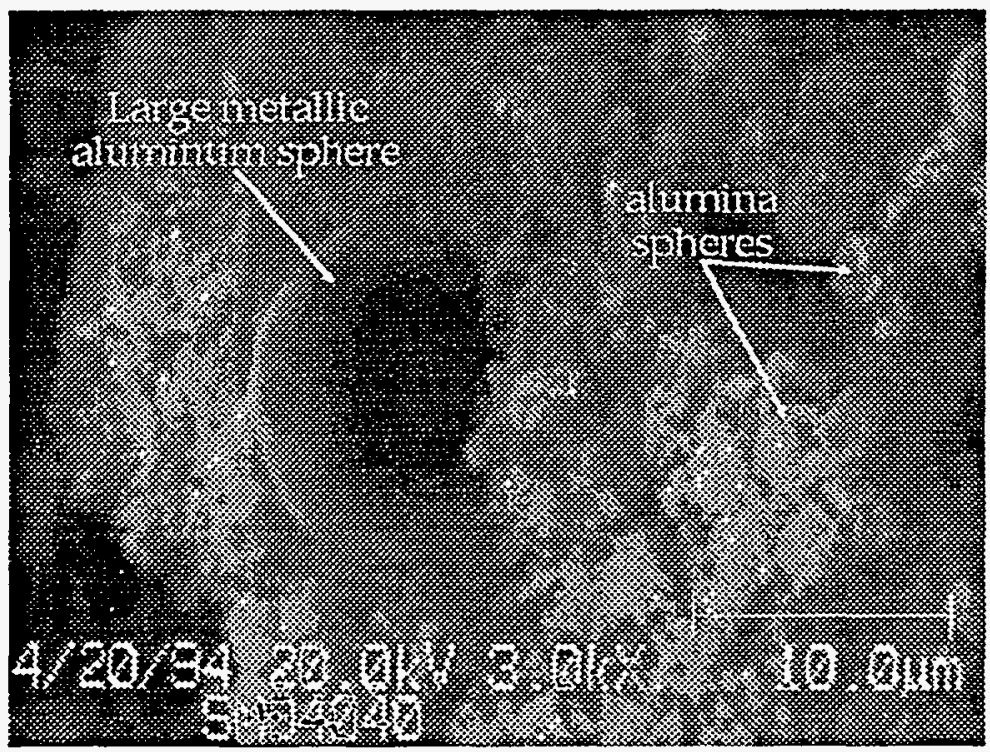

\section{Thermal stability and reaction exotherms}

\section{Differential scanning calorimetry (DSC)}

We replicated the unusual exotherm that had been reported to us by heating the ultradispersed aluminum to $700^{\circ} \mathrm{C}$ in the DSC. We tested the samples in open platinum pans, at a heating rate of $10^{\circ} \mathrm{C} /$ minute, both in ultrapure helium $(99.999 \%)$ and in nitrogen (>99\%). We performed the thermal tests before the other characterization described above was completed, and were not sure of the airstability of the ultradispersed aluminum; therefore, we handled the samples in a nitrogen-flushed glovebag to reduce exposure to air. Results are shown in Figure 11. Significant exotherms are seen before the aluminum melting endotherm in both cases. A crude estimation of the areas under the exotherms indicates energy releases of $1000-4000 \mathrm{~J} / \mathrm{g}$ (higher value is with helium, where the exotherm and melting endotherm are better separated), which is the same order of magnitude as the energy of detonation of TNT of $\approx 4000 \mathrm{~J} / \mathrm{g}$. These estimates are very imprecise, but show a significant release of energy from this material. For comparison, DSC traces for standard aluminum are shown in Figure 12, where the only significant thermal feature is the melting of the aluminum. 
Figure 11. DSC traces for ultradispersed aluminum in helium and nitrogen atmospheres. Large exotherm is seen prior to endotherm of melting. Area of exotherm corresponds to $1000-4000 \mathrm{~J} / \mathrm{g}$, comparable to the exotherm energies of energetic materials.
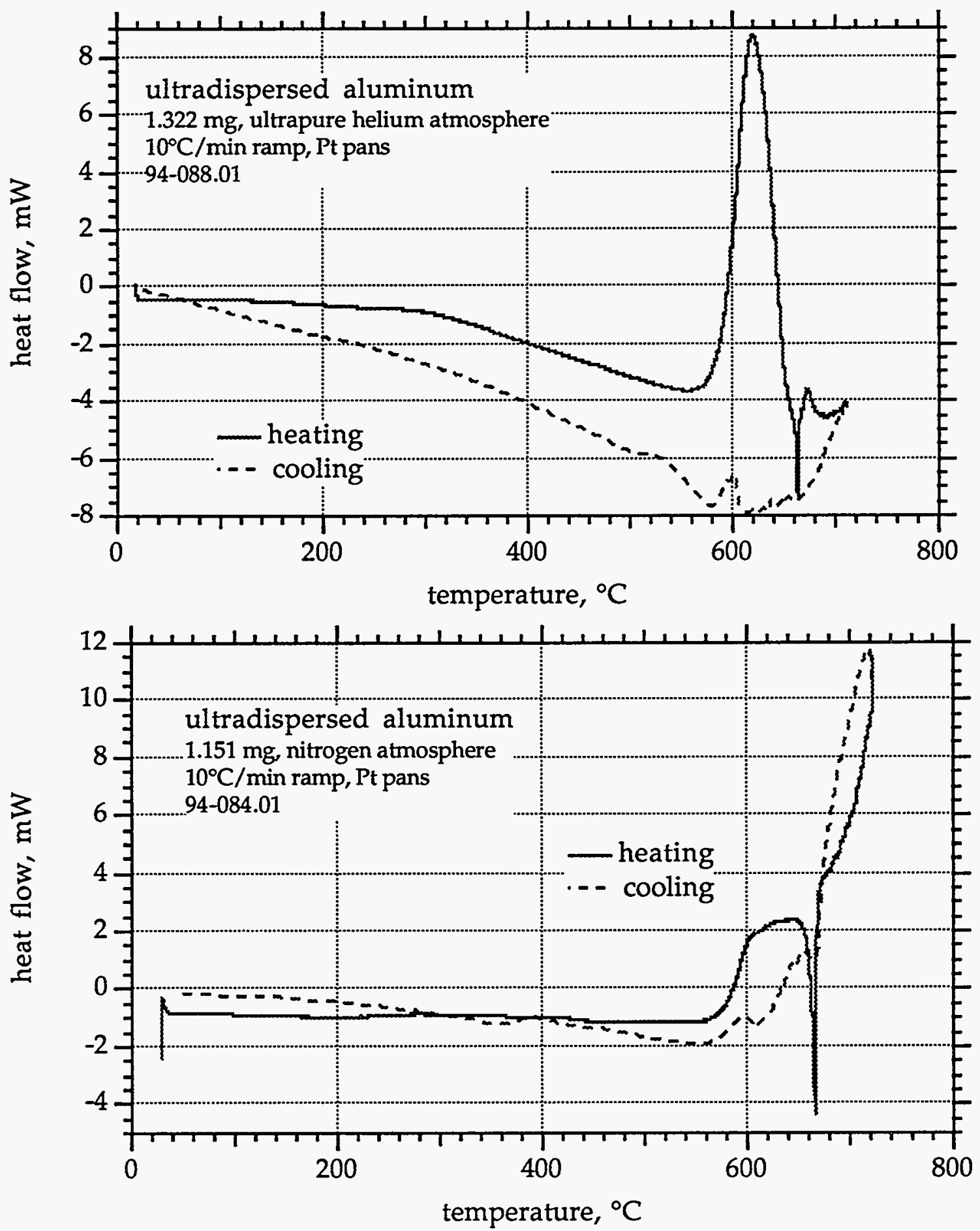
Figure 12. DSC traces for standard aluminum in helium and nitrogen atmospheres. No large exotherm is seen for this material - only the endothermic melting and exothermic freezing of the aluminum.

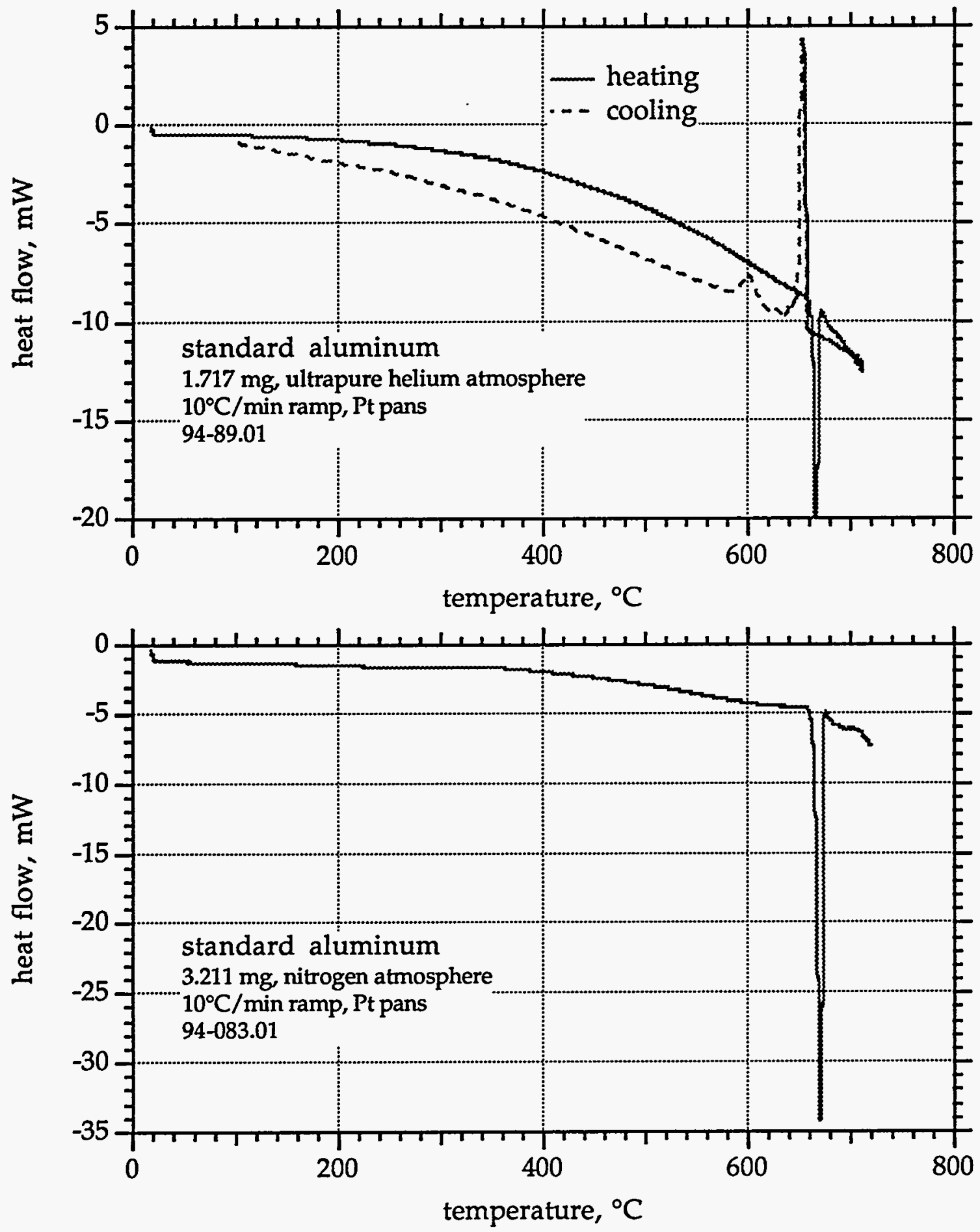


We also tested the stability in air of the ultradispersed aluminum at room temperature by holding the material in air for a long period at room temperature and monitoring the heat flow with the DSC. The results, shown in Figure 13, show a total heat flux of less than $70 \mathrm{~mJ}$ for a $1.34 \mathrm{mg}$ sample over a 55 minute duration. This mass of aluminum, if fully oxidized, would release $42 \mathrm{~J}$ of heat, so the observed $70 \mathrm{~mJ}$ represents less than $0.2 \%$ oxidation during the 55 minute air exposure; even with the limited accuracy of this measurement due to baseline drift during the long soak, there is clearly little oxidation of the sample during this time.

Figure 13. DSC trace for ultradispersed aluminum held at room temperature in ambient air for 55 minutes. The observed heat flow of $\leq 70 \mathrm{~mJ}$ corresponds to less than $0.2 \%$ oxidation of the sample during the exposure to air.

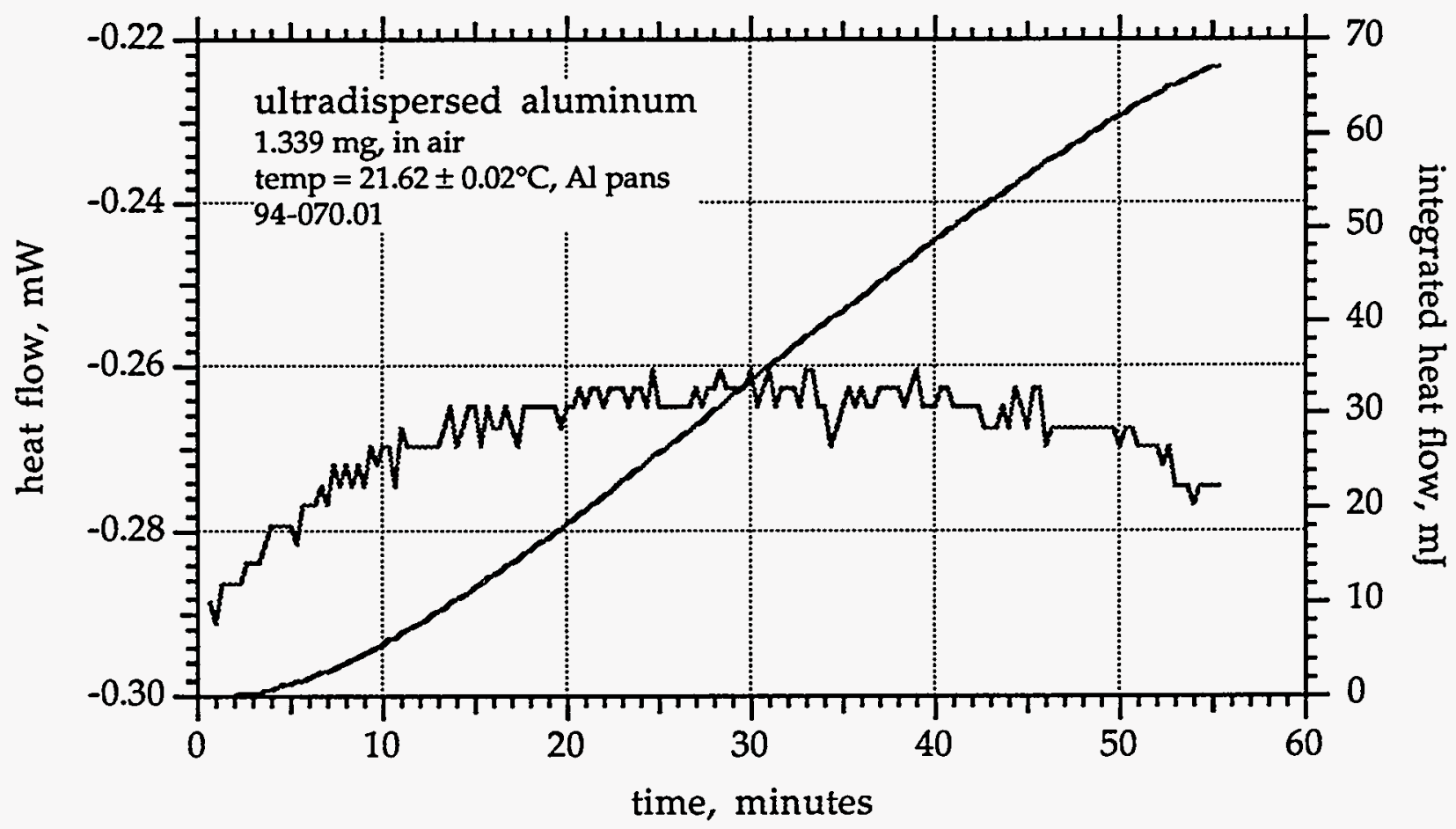

\section{Differential thermal analysis/thermogravimetric analysis (DTA/TGA)}

To identify the source of the exotherm seen with ultradispersed aluminum, we turned to simultaneous DTA/TGA. In this instrument, samples of 1-3 mg were held in platinum cups and thermally cycled, while the temperature difference between the sample and a reference mass was monitored along with the mass of the sample. We performed all runs with ultrapure helium ( $99.999 \%$ purity).

DTA/TGA runs with ultradispersed aluminum and standard aluminum are shown in Figure 14. The standard aluminum shows only the melting/freezing transition, with no increase in sample mass. We see the same exotherm in the ultradispersed aluminum as in the DSC, but there is clearly an associated mass increase which continues through the entire run; the sample is reacting, presumably 
with impurities in the gas, to form a heavier product. The freezing transition is greatly diminished with the ultradispersed aluminum, again indicating that most of the aluminum has been converted to another compound.

Figure 14. DTA/TGA traces for ultradispersed aluminum and standard aluminum in helium. The standard aluminum shows only the melting/freezing transition, and is of constant mass. The ultradispersed aluminum shows the exotherm prior to the melting endotherm, as with DSC, with a corresponding mass increase.
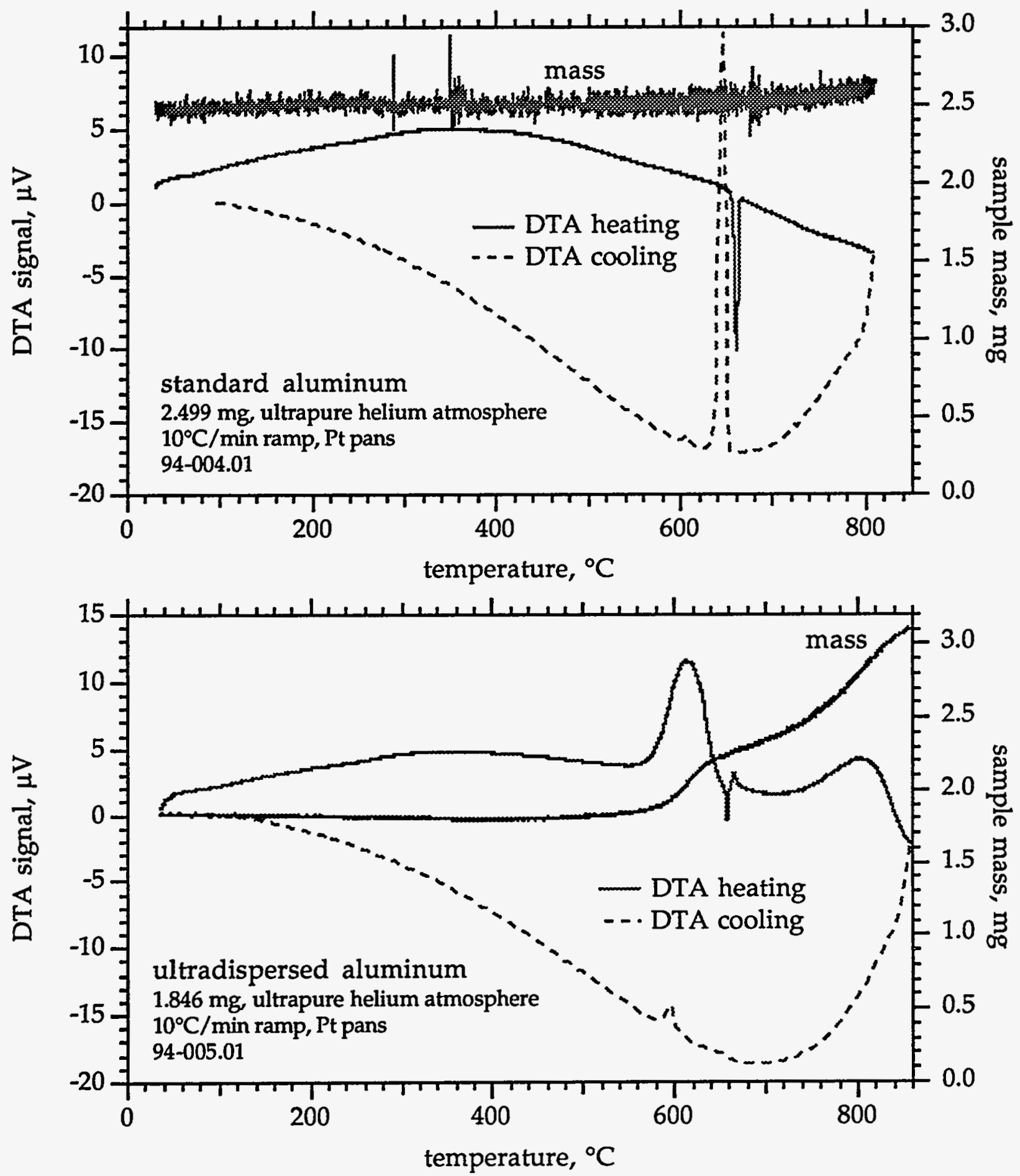
We next ran an ultradispersed aluminum sample and held it at the final temperature of $840^{\circ} \mathrm{C}$ for 45 minutes. The results are shown in Figure 15. The mass increased from $1.533 \mathrm{mg}$ to $2.485 \mathrm{mg}$ during heating, and increased further to 2.717 $\mathrm{mg}$ after the 45-minute soak. If the aluminum were completely converted to $\mathrm{Al}_{2} \mathrm{O}_{3}$, (the gaseous reactant is water, as shown below) the sample mass would have been $2.897 \mathrm{mg}$; the mass increases in Figure 15 correspond to $70 \%$ of the aluminum oxidizing during heating and an additional $17 \%$ oxidizing during the 45 -minute hold. Clearly the aluminum was not oxidized before the thermal cycle, consistent with the other analyses reported above. In addition, the oxidation reaction went essentially to completion, indicating that a very thin passivation layer had been formed on the fine-particle aluminum.

Figure 15. DTA/TGA trace for ultradispersed aluminum, heated to $840^{\circ} \mathrm{C}$ and held for 45 minutes. The sample mass increased from $1.533 \mathrm{mg}$ to $2.485 \mathrm{mg}$ during heating and increased further to $2.717 \mathrm{mg}$ during the 45-hold.

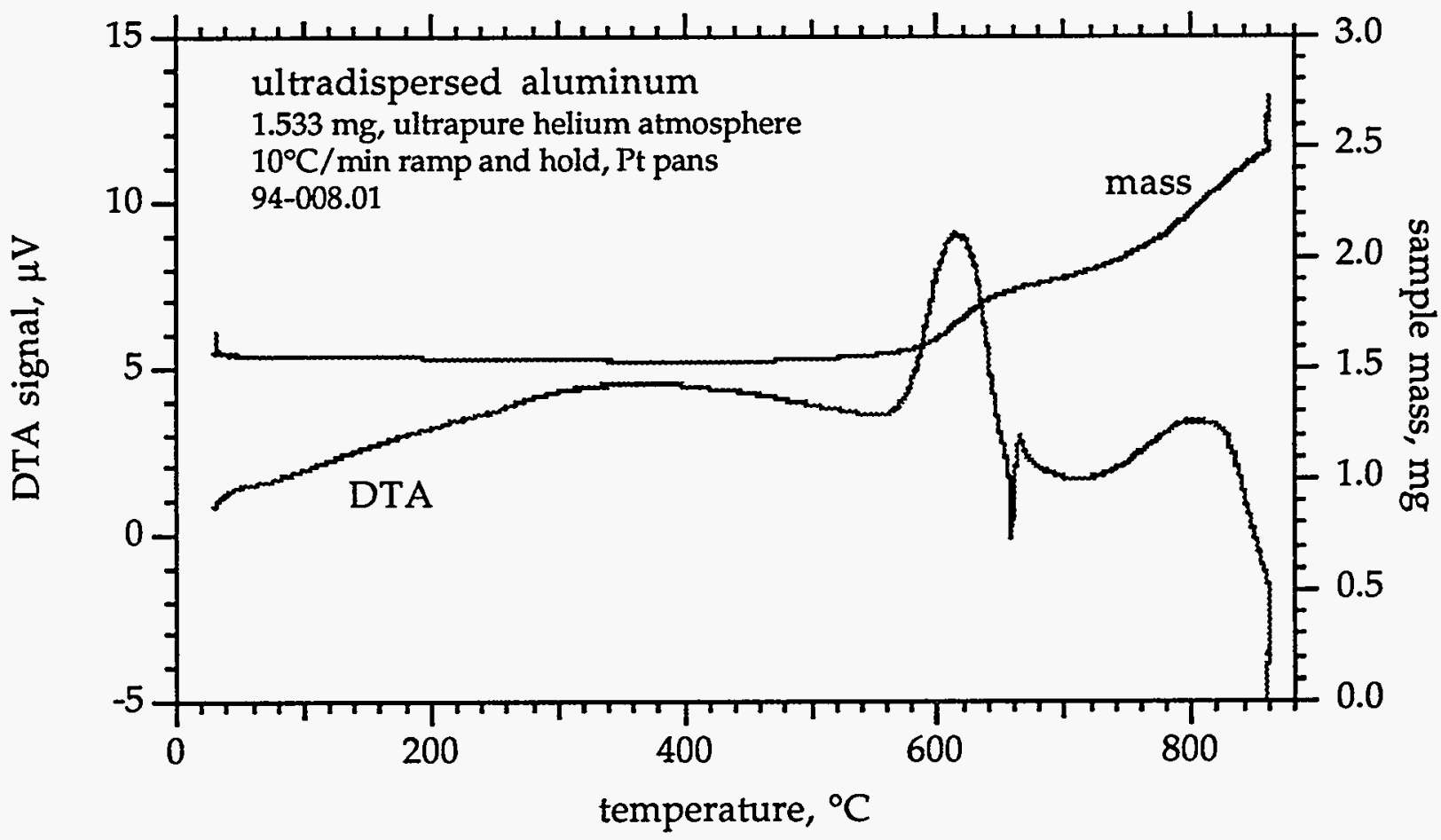

We suspected that the aluminum was reacting with moisture in the DTA/TGA during heating, despite the use of ultrapure helium. Some moisture is admitted to the DTA/TGA when it is opened for sample insertion, and there is some adsorbed on surfaces in the instrument; we did not flush the DTA/TGA (or the DSC) to remove this moisture. To check this, we routed the gas leaving the DTA/TGA through a moisture meter, which measured moisture levels of 1-1000 ppm (higher readings are outside the calibration range), and recorded the moisture level during a simulated run with no sample, but with the temperature cycled up to $800^{\circ} \mathrm{C}$ at $20^{\circ} \mathrm{C} /$ minute. The moisture level of the gas leaving the DTA/TGA was 
initially quite high, and stayed above $500 \mathrm{ppm}$ throughout the entire run, as seen in Figure 16. This quantity of moisture is sufficient to react with the small sample in the DTA/TGA.

Figure 16. Moisture level in ultrapure helium gas leaving DTA/TGA during simulated run to $800^{\circ} \mathrm{C}$ at $20^{\circ} \mathrm{C} /$ minute. There is sufficient moisture adsorbed on the internal surfaces and admitted during sample loading to oxidize the aluminum during a thermal analysis run, despite the use of ultrapure helium.

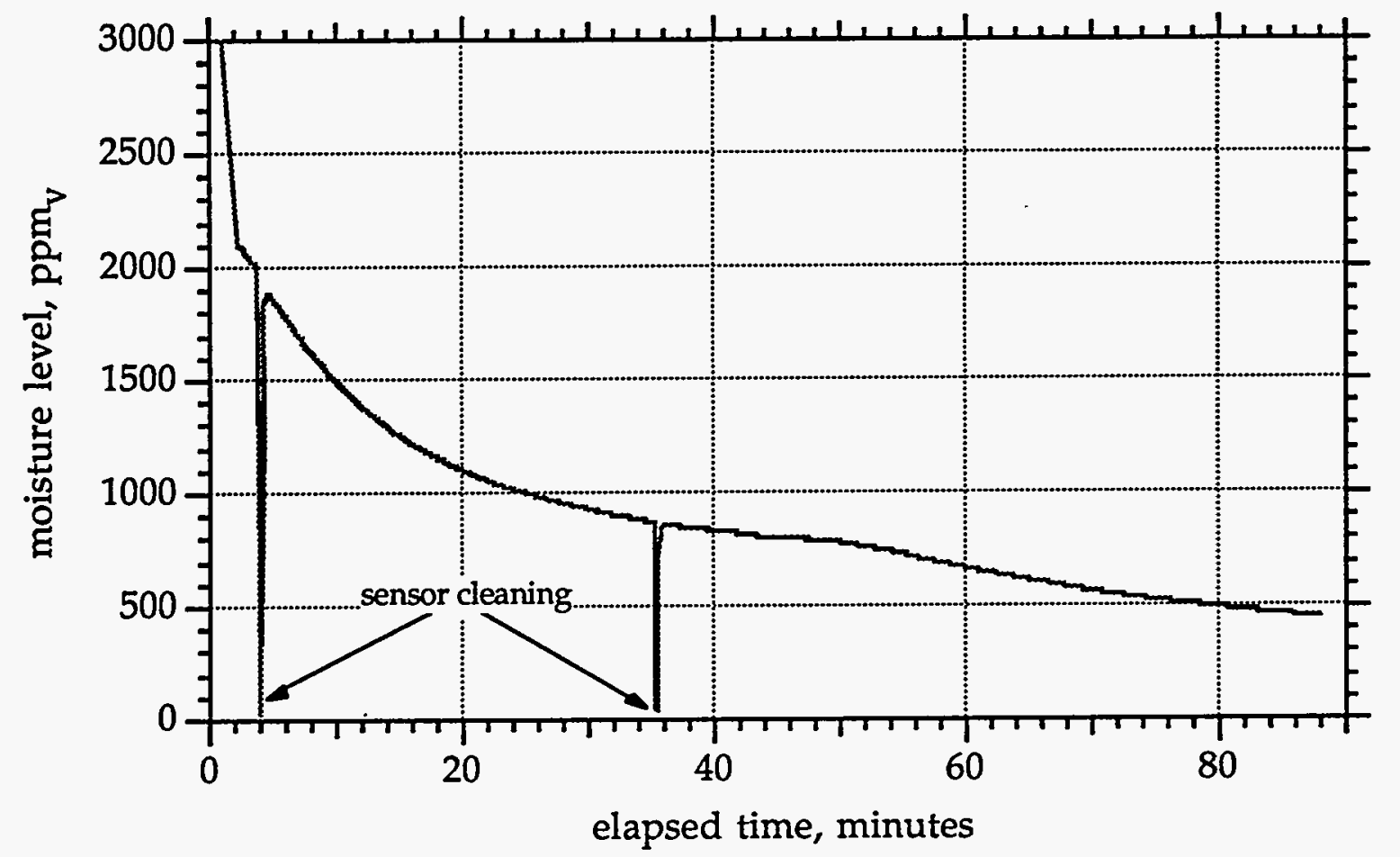

To verify that moisture was reacting with the ultradispersed aluminum in the DTA/TGA, we ran two experiments where we removed as much moisture as possible by purging the unit with ultrapure helium for many hours after loading the sample, before running the thermal cycle. The results are shown in Figures 17 and 18. In the first run, Figure 17 , we flushed at room temperature for $\approx 41$ hours, and flushed at $60-75^{\circ} \mathrm{C}$ for another 3 hours before running the thermal cycle. The exotherm during the heating cycle is not present, although we do see some mass increase. There was moisture present during this run, $380 \mathrm{ppm}$ at start of run and $615 \mathrm{ppm}$ at end, illustrating the difficulty in removing moisture from an unbaked system. To get lower moisture levels, and to ensure that the flushing at $60-75^{\circ} \mathrm{C}$ did not pre-react some of the aluminum, we ran another test (Figure 18) where we flushed at room temperature for 65 hours before running the thermal cycle. Here the moisture levels were more constant during the run $(480 \mathrm{ppm}$ at start, $450 \mathrm{ppm}$ at end), and again there was no exotherm during the heating cycle. There is still sample mass increase, consistent with the amount shown in the previous figure, but much less than was observed in the runs with no flushing. These experiments with the flushed system demonstrate that the exotherm observed during heating of the ultradispersed aluminum was the result of reaction of the aluminum with moisture admitted to and adsorbed in the DTA/TGA and DSC systems. 
Figure 17. Moisture level in DTA/TGA during flush after sample loading, and DTA/TGA trace for ultradispersed aluminum in the flushed system. Flush was conducted mostly at room temperature, with three hours at $60-75^{\circ} \mathrm{C}$. The exotherm previously observed during heating is not present, and the sample mass increase is small (1.941 to $2.162 \mathrm{mg}$ ), indicative of only minor reaction of the sample with moisture.
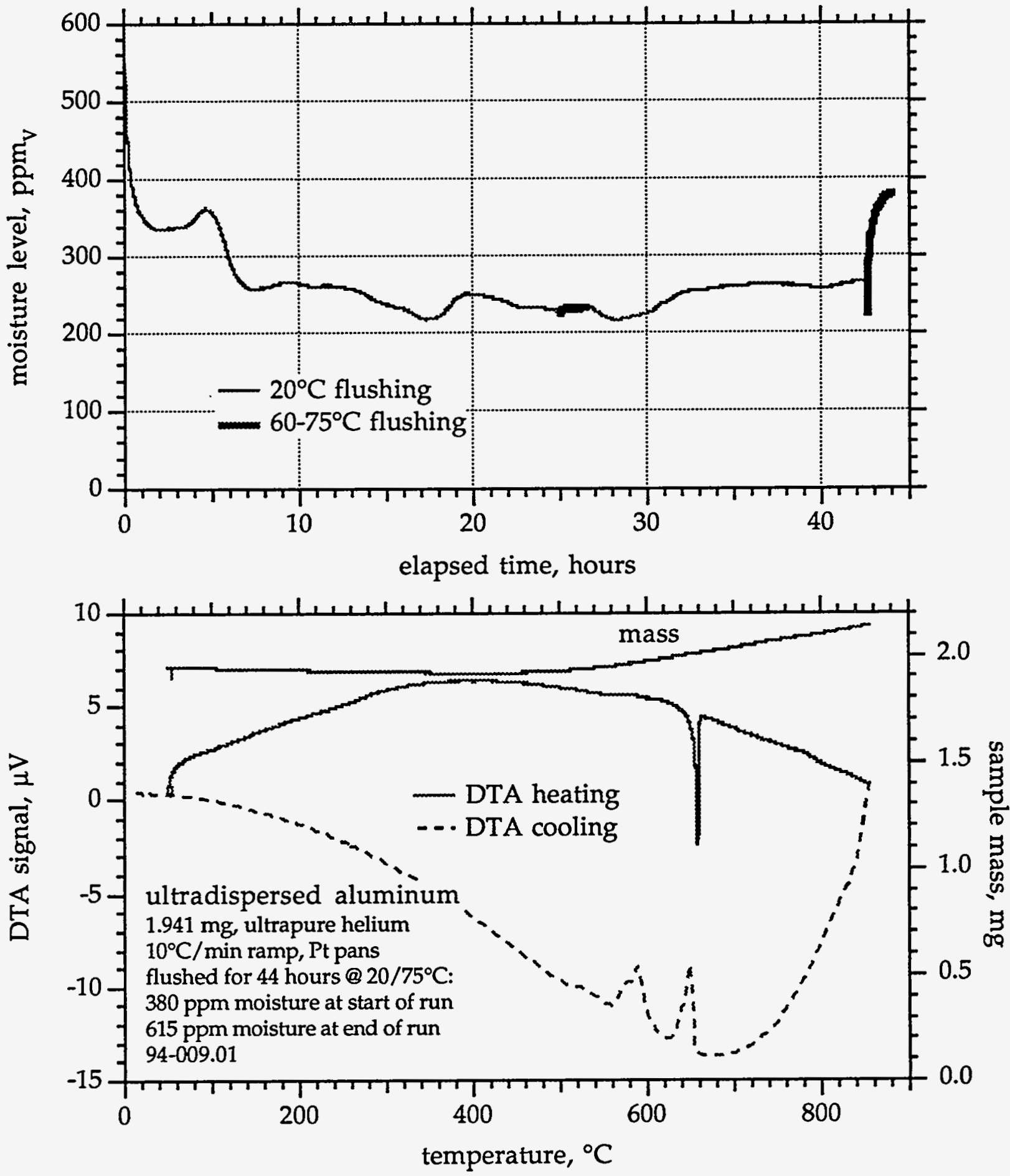
Figure 18. Moisture level in DTA/TGA during flush after sample loading, and DTA/TGA trace for ultradispersed aluminum in the flushed system. Flush was conducted at room temperature. Moisture levels after the longer flush are lower than those in the run in Figure 17. Again, the exotherm previously observed during heating is not present, and the sample mass increase is small (1.863 to 2.071 $\mathrm{mg}$ ), indicative of only minor reaction of the sample with moisture.
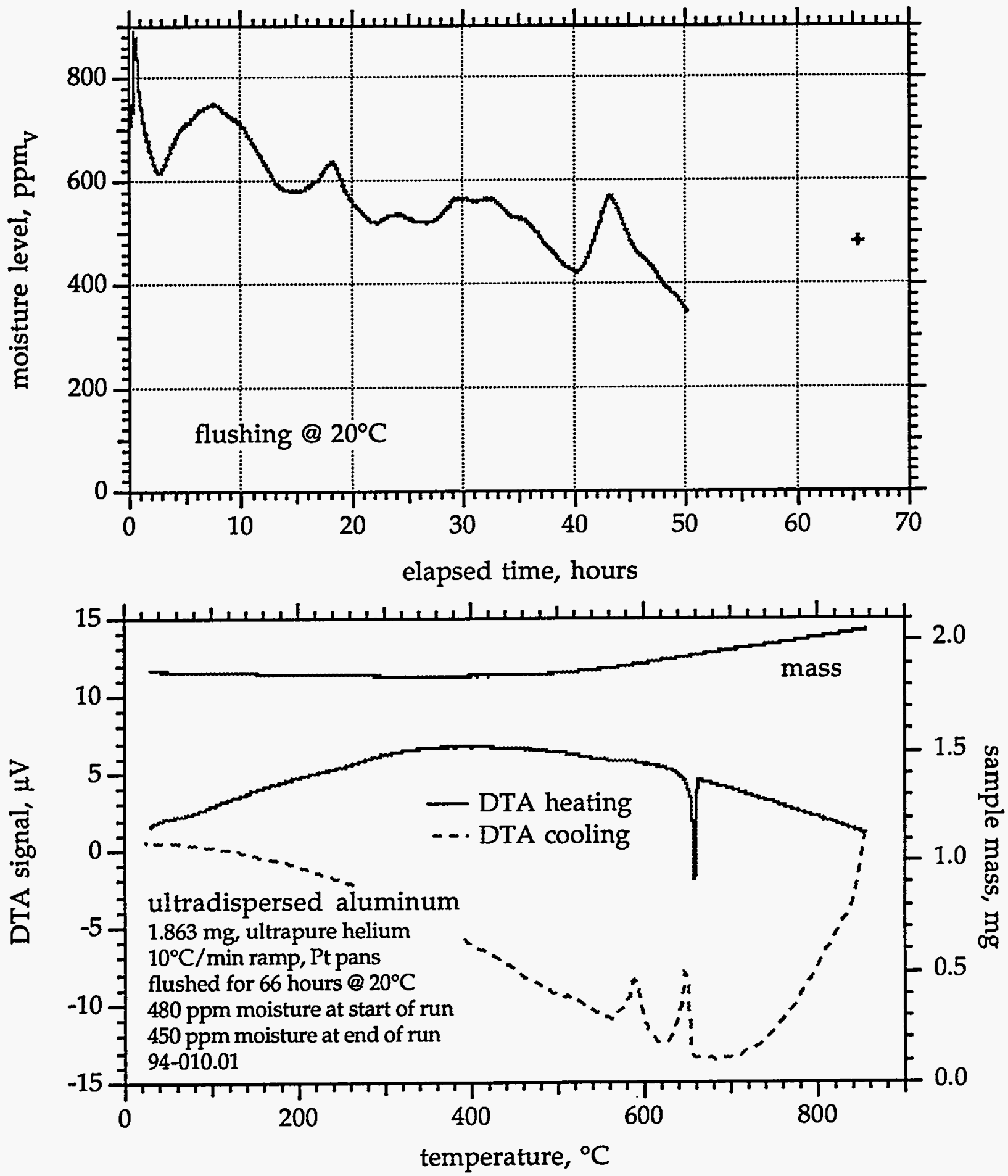
The mass increases in these two runs showed that $13 \%$ of the aluminum was oxidized in each run; the moisture present at $400-600 \mathrm{ppm}$ despite the prolonged flushing was sufficient to give this extent of reaction. Since we saw no exotherm from this reaction, we conclude that the reaction was very slow (presumably limited by availability of moisture) and and the energy release was spread over a wide temperature range during the heating ramp.

\section{Summary}

The ultradispersed aluminum consists of an agglomeration of very small (100-300 nm diameter) spherical aluminum particles. The surface area is very high, consistent with the very small particle diameters. There is a thin aluminum oxide layer ( $\approx 2 \mathrm{~nm}$ thick) on the surface, which gives the material stability at room temperature in ambient air despite the high surface area. The ultradispersed aluminum is only slightly degraded at $700^{\circ} \mathrm{C}$ in vacuum, but does react with moisture at $\approx 600^{\circ} \mathrm{C}$.

The density of the material is that of pure aluminum. We could find no indication of argon in the ultradispersed aluminum. Because we applied a wide range of techniques, we conclude that there is no argon present, either on the surface, occluded in the bulk phase, or as a compound. The material is very pure aluminum.

The exotherm at elevated temperature is caused by reaction of the highlyreactive aluminum with residual moisture in the DSC or DTA/TGA apparatus. When the moisture is removed by flushing, the exotherm disappears and the ultradispersed aluminum thermal response is essentially identical to that of standard aluminum.

In short, the inexplicable reports of an aluminum-argon compound and of an exothermic reaction from the ultradispersed aluminum are in fact not borne out by our studies. Nonetheless, the ultradispersed aluminum is a stable, non-oxidized, small particle, highly-reactive form of aluminum that is of interest in energetic materials formulations.

\section{Acknowledgments}

We would like to thank Mr. James Yoshiama for the SEM work, Ms. Suzanne Hulsey for the BET surface area analysis, Mr. Michael Sharp for the spark emission spectroscopy, Dr. Ronald Musket for the PIXIE and RBS analysis, Dr. Hugh Gregg for $X$-ray fluorescence analysis, and Dr. Marcus Schildbach for SAM.

We also acknowledge Dr. William Stevens and Dr. LeVaughn Hales of MICOM for supplying us with the samples of ultradispersed aluminum. 